\title{
Controlling Cell Behavior Through the Design of Polymer Surfaces
}

\author{
Natália M. Alves, Iva Pashkuleva, Rui L. Reis, and João F. Mano*
}

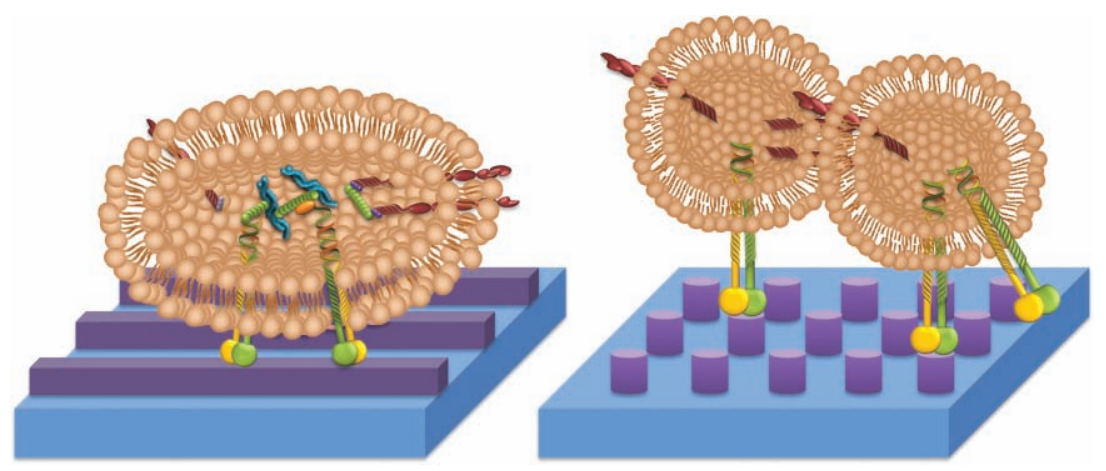

\section{From the Contents}

1. Introduction ..................

2. Cell Response to Topographical Signals ... 2

3. Cell Response to Chemical and Biomolecular Signals..................

4. Smart Textures .................... 10

5. Future Trends............... 12
Polymers have gained a remarkable place in the biomedical field as materials for the fabrication of various devices and for tissue engineering applications. The initial acceptance or rejection of an implantable device is dictated by the crosstalk of the material surface with the bioentities present in the physiological environment. Advances in microfabrication and nanotechnology offer new tools to investigate the complex signaling cascade induced by the components of the extracellular matrix and consequently allow cellular responses to be tailored through the mimicking of some elements of the signaling paths. Patterning methods and selective chemical modification schemes at different length scales can provide biocompatible surfaces that control cellular interactions on the micrometer and sub-micrometer scales on which cells are organized. In this review, the potential of chemically and topographically structured micro- and nanopolymer surfaces are discussed in hopes of a better understanding of cell-biomaterial interactions, including the recent use of biomimetic approaches or stimuli-responsive macromolecules. Additionally, the focus will be on how the knowledge obtained using these surfaces can be incorporated to design biocompatible materials for various biomedical applications, such as tissue engineering, implants, cell-based biosensors, diagnostic systems, and basic cell biology. The review focusses on the research carried out during the last decade. 


\section{Introduction}

The initial concept of investigating materials and biological systems at the micro- and nanoscale dates back to 1959 , when Richard Feynman presented a lecture, entitled "There's Plenty of Room at the Bottom." This talk is generally considered to be the first look into the world of materials, species, and structures at nanoscale levels (Figure 1).

Almost 30 years later, in 1986, Drexler defined a new scientific field called nanotechnology. ${ }^{[1]}$ Rapidly advancing and adopted at once by other scientific areas such as engineering, physical, life and medical sciences because of its ability to shape matter on the scale of molecules, nanotechnology opened the door to a new generation of surfaces applicable in diagnostics, therapeutics, imaging agents, and other fields. Using the tools of nanotechnology, the researchers started to learn from nature how to create new micro- and nanoscale devices to better understand life processes at the nanoscale. A new highly interdisciplinary area called nanobiotechnology (NBT) was established. With the help of NBT, we now realize that living cells are complex entities presenting a remarkable, inherent capacity to sense, integrate, and respond to environmental cues at the microand nanoscale. ${ }^{[2]}$ Their native environment is a $3 \mathrm{D}$ scaffold comprising an insoluble aggregate of several highly organized, multifunctional large proteins and glycosaminoglycans (GAGs), collectively known as the extracellular matrix (ECM). The ECM provides a mechanical support for cells (most mammalian cells are anchorage-dependent; i.e., they must adhere to a surface in order to survive), but it also profoundly influences the fundamental cellular functions (e.g., migration, proliferation, differentiation, and apoptosis) of the cells with which it is in contact (Figure 2). By interacting directly with the ECM, cells gather information about the chemical and physical nature of the environment, integrate and interpret it, and then generate an appropriate physiological response. ${ }^{[2 b, 3]}$ Keeping in mind this extreme intelligence and sensitivity of cells, it seems convenient that their behavior can be directed through precisely designed environment.

Although there are extensive reports in the literature about controlling and manipulating cell behavior on patterned model surfaces, such as in inorganic materials and metals, we will focus only on polymer surfaces. Due to their great versatility in chemical composition, properties, and processing techniques, polymers have been used in many biomedical applications, including tissue engineering scaffolds and distinct implants. There are now a variety of possibilities for changing the spatial arrangement of chemical and topographic motifs on polymeric substrates (Figure 3), which could be specifically useful for such applications. Hence, the discussion of how to control cell behavior in designed polymer surfaces is particularly relevant and will be focused upon in this review.

\section{Cell Response to Topographical Signals}

The developments in micro- and nanofabrication technologies, such as soft-, photo- and electron-beam lithography, have allowed for the production of patterns (Figure 3 ) and the analysis of cell behavior on patterned surfaces. ${ }^{[2,4]}$ Nowadays, it is possible to probe the effects of structures with dimensions on the order of cell dimensions or smaller. Studies focusing on cell behavior on surfaces with micrometer-sized features revealed that such surfaces can induce cell polarization and direct cell migration, and can even regulate gene expression and cell signalling. ${ }^{[5]}$

Prof. N. M. Alves, Prof. I. Pashkuleva, Prof. R. L. Reis, Prof. J. F. Mano 3B's Research Group - Biomaterials Biodegradables and Biomimetics University of Minho

Headquarters of the European Institute of Excellence on Tissue Engineering and Regenerative Medicine AvePark, 4806-909 Taipas, Guimarães, Portugal E-mail:jmano@dep.uminho.pt

Prof. N. M. Alves, Prof. I. Pashkuleva, Prof. R. L. Reis, Prof. J. F. Mano IBB - Institute for Biotechnology and Bioengineering

PT Associated Laboratory

Guimarães, Portugal

DOI: $10.1002 / \mathrm{smll} .201000233$ 


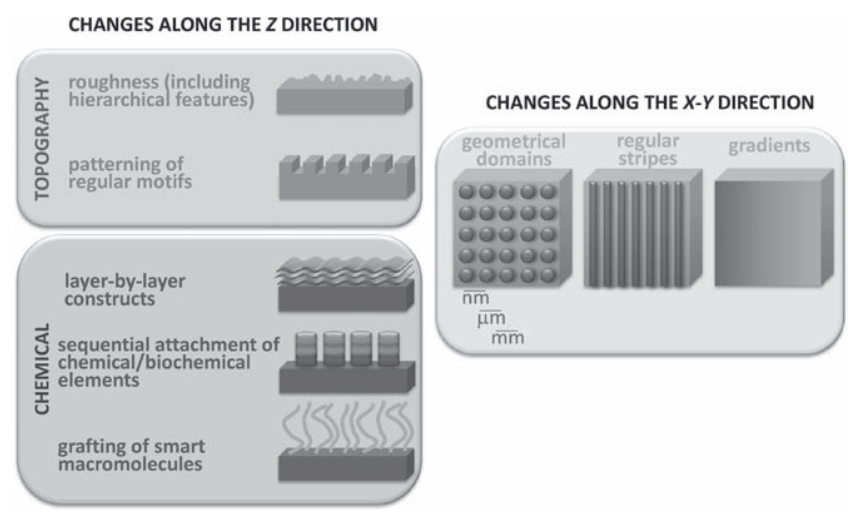

Figure 3. Different approaches for tailoring the surface morphology and chemistry.

\subsection{Surfaces with Regular Topographies}

The effects of ordered textures, in particular microgrooves and -ridges, on different cell types have been analyzed by many authors. ${ }^{[6]}$ Typically, the cells become elongated and aligned in the direction of the grooves, and they migrate as guided by the grooves. ${ }^{[6 \mathrm{~b}]}$ This phenomenon is known as contact guidance. It has also been found that the degree of alignment depends on the groove depth and width ${ }^{[6 b]}$ and varies between different cells. Generally, the studies on the effect of microgrooves on cell behavior have shown that the extent of orientation increases with groove depth up to $25 \mu \mathrm{m}$ from topographies of $\sim 1 \mu \mathrm{m}$. Based on these findings, some authors suggested that these physical cues should not be greater than the actual size of the cell. ${ }^{[6]}$ Ber et al. ${ }^{[7]}$ also found that osteoblasts aligned and oriented on micropatterned collagen films within this size range, but they did not observe this when macropatterns were used. The differences in the morphological behavior between fibroblasts cultured on nanogrooved (groove depth: 5-350 nm, width: 20-1000 nm) and smooth polystyrene substrates were analyzed recently in detail in order to clarify to what extent cell guidance occurs on increasingly smaller topographies. ${ }^{[8]}$ It was found that fibroblasts do not align on surfaces with groove depths below $35 \mathrm{~nm}$ or ridge widths smaller than $100 \mathrm{~nm}$. The effect of other patterns, such as pillars and pits, has also been analyzed, ${ }^{[9]}$ with cell proliferation thought to be increased with decreasing pit diameter ${ }^{[10]}$ and cell attachment thought to be larger on microscale pillars than on macroscale pits. ${ }^{[1]}$

Besides the traditional lithographic processes that can be used to obtain patterned surfaces, more recent alternative methodologies have been suggested, ${ }^{[12]}$ based on the morphology generated by the microphase separation of diblock copolymers, the self-assembly of a mixture of homopolymer blend and diblock copolymers, and the macroscopic phase separation of homopolymers blends. These simple and quite cheap procedures allow the production of patterns with feature sizes from tens of nanometers to a few micrometers onto a substrate. For example, polymer demixing was used to produce randomly distributed circular, channel-like pits or island textures with controlled depths and heights from 10 to $100 \mathrm{~nm} \cdot{ }^{[13]}$ Nanotextured poly-L-lactic acid/polystyrene

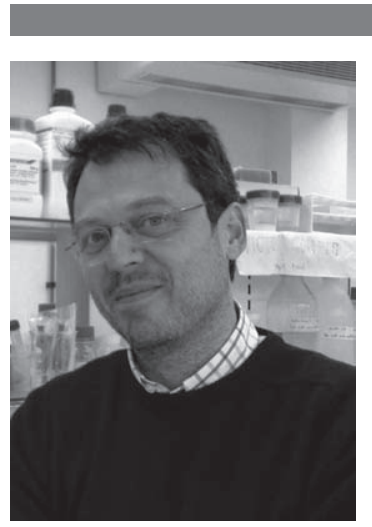

João F. Mano received his PhD in Chemistry in 1996 from the Technical University of Lisbon, and currently is teaching at the University of Minho. His current research interests include the development of materials, especially derived from natural-based biodegradable polymers, that can react to external stimuli, or biomimetic and nanotechnology approaches applied to biomaterials to be used in tissue engineering and controlled drug delivery. JFM is author of more than 240 papers in international journals, he has been involved in several national and European research projects and in the

organization of scientific events on polymer/materials science and biomaterials/tissue engineering.

(PLLA/PS) films obtained by this methodology stimulated greater osteoblastic cell adhesion and spreading than did flat control films; the adhesion and spreading was particularly noted on surfaces with a nanoisland topography. ${ }^{[13 c]}$ Ultrathin films of diblock copolymers based on polystyrene/ poly(4-vinylpyrindine) that assemble on mica to form heterogeneous surface patterns have been prepared. ${ }^{[14]}$ The size and morphology of these nanopatterns, which contain dotlike, wormlike, or both features, depend essentially on the relative length of the blocks; as a result, they can be controlled and are highly reproducible. ${ }^{[14]}$ It was found that nanopatterns of heights less than $10 \mathrm{~nm}$ elicit distinct rates of adhesion and proliferation in fibroblasts and mesenchymal precursor cells, although both cell types adhered and proliferated better in the wormlike, coated substrate. ${ }^{[14 b]}$ The distinct cell types also affected the ECM environment differently during their migration. ${ }^{[14 b]}$

Other innovative approach is the use of carbon nanotubes to produce patterns on polymeric substrates. Eliason et al. fabricated polymer substrates exhibiting micropatterns of carbon nanotubes by an imprint process where the nanotubes were pressed into a polycarbonate layer at high temperature. ${ }^{[15]}$ The micropatterns consisted of lines and circles with sizes ranging from 1 to $75 \mu \mathrm{m}$. Moreover, since the nanotubes present a nanometer-scale roughness, this methodology constitutes an intelligent way of combining micro- and nanotopography. The authors found that the alignment of osteoblastlike cells was significant on the line patterns, and no alignment occurred on the circles patterns.

Nanofibers can be produced by electrospinning, in which meshes with different properties may be produced, including meshes composed by aligned nanofibers. ${ }^{[16]}$ Such aligned nanofibers also affect cell behavior. In fact, it has been shown that proliferation, alignment of cells, and gene regulation depend strongly on the orientation of the fibers. ${ }^{[17]}$

\subsection{Influence of the Surface Roughness}

In addtion to the type of pattern, surface roughness is a parameter that can also influence cell behavior. Random surface topographies are more easily fabricated and less 
expensive. Different techniques can be used to obtain such as topographies, namely the already-mentioned polymer demixing technique, chemical etching, plasma treatments, or electrospinning. For example, human vascular endothelial cells were cultured on electrospun and solvent-cast PLLA substrates with different surface roughnesses (but without a pattern) and cell phenotype; ${ }^{[18]}$ adhesion and proliferation were significantly improved on smooth surfaces. In addition, the cell morphology was completely different on the rough substrates. ${ }^{[18]}$ While anisotropic topographies, such as ridges and grooves, affect the individual cell behavior (cells align along the anisotropic direction), isotropic topographies, such as evenly or randomly distributed pits or protrusions (Figure 3), obtained by treating the substrates with plasma at specific conditions, affect collective cell behavior (Figure 4). The work reported by Owen et al. ${ }^{[19]}$ illustrates well how it is possible to induce specific cell behavior by changing surface topography. In this study, poly(lactic-co-glycolic acid) (PLGA) membranes presenting smooth, grooved, and sandblasted-acid-etched surfaces were prepared. The authors found that rough PLGA surfaces inhibited epithelial cell attachment, migration, and proliferation in vitro more than the smooth PLGA surface. The effects of smooth and grooved PLGA surfaces on osteoblast attachment, proliferation, and migration were also analyzed, and it was found that the grooved surfaces directed migration and supported the production of mineralized tissue. Such membranes could find clinical applications in periodontal guided tissue regeneration, where cells from distinct origins contact different sides of the membrane. For example a grooved surface could be placed on the membrane facing a bone defect to guide osteoblasts to the defect area, whereas the rough (but without a symmetric pattern) surfaces could be produced on the upper surface that contact epithelium in order to inhibit epithelial migration and proliferation.

\subsection{Other Surface Parameters Influencing Cell Behavior: Wettability, Stiffness, Crystallinity}

Changes in the roughness also induce changes in the wettability of the surfaces. It is well known that cell adhesion and protein adsorption onto a substrate are highly affected by the wettability and chemical nature of the surface. ${ }^{[20]}$ It was found that cells present a maximum attachment capability onto surfaces with moderate wettability: for the case of surfaces with controlled chemistry produced by self-assembled monolayers, maximum adhesion was reached for contact angles between $40^{\circ}$ and $60^{\circ}{ }^{[20 \mathrm{a}]}$ The results suggested that cell attachment is mainly determined by surface wettability, but it is also affected by the surface functional groups, their surface density, and of course, the kind of cells. Also, the effect of wettability of biomaterials has been mainly investigated in flat substrates. However in tissue engineering applications, cells are within a $3 \mathrm{D}$ environment, so it would be more appropriate to analyze this effect on 3D samples. It was shown that scaffolds with different wettabilities could be produced by using copolymers containing different compositions of hydrophilic and hydrophobic repeating units, enabling the production of model porous structures with controlled hydrophilicities. ${ }^{[21]}$ It would be interesting to use such scaffolds to analyze the wettability effect on cells in a 3D environment. Another drawback of conventional wettability studies is that they are limited to surfaces ranging from hydrophilic to hydrophobic because smooth surfaces have been typically used. There is both fundamental and practical interest in extending such studies towards the superhydrophilic (contact angles below $5^{\circ}$ ) and superhydrophobic (contact angles higher than $150^{\circ}$ ) limits. For example, new insights may be obtained on the influence of such extreme environments on the physiological response of cells, including their contractile characteristics and signalling activity that may influence adhesion, morphology/anisotropy, migration, proliferation, and differentiation. The only
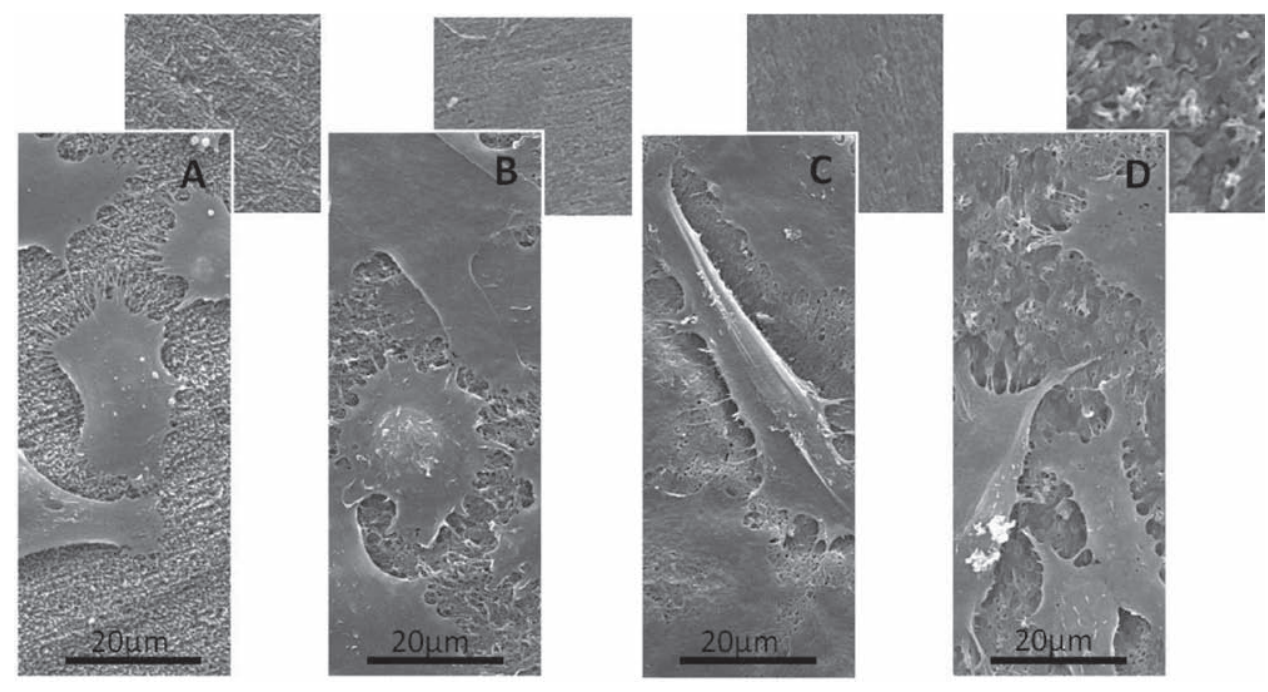

Figure 4. Cell response (SaOs-2 cells, 2 days) to different surface morphologies (the small squares up) obtained by the plasma treatment of a blend of starch with ethylene vinyl alcohol (SEVA; 50/50 wt\%) at the following conditions: a) 10 min in $\mathrm{O}_{2}$ and applying a power of $30 \mathrm{~W}$; b) 30 min, $\mathrm{O}_{2}$, $80 \mathrm{~W}$; c) $5 \mathrm{~min}$, argon, $30 \mathrm{~W}$; and d) untreated SEVA. 
possibility to reach such extreme contact angles is to prepare surfaces with special roughness features. By mimicking the effects found in nature, such as in the lotus leaf in which the surface exhibits extreme water repellence, PLLA biomimetic surfaces that combine nano- and micro-level roughness were developed. ${ }^{[22]}$ Such surfaces were found to be highly hydrophobic, exhibiting water contact angles above $150^{\circ}$. The behavior of bone-marrow-derived cells in contact with these PLLA surfaces was found to be significantly affected by superhydrophobicity: such rough surfaces inhibit cell adhesion and proliferation more than a flatter surface would. [22] Moreover, by using plasma treatments the hydrophilic nature of the polymer could be changed, and the wettability of such initial rough substrates could be tailored between the superhydrophobic and superhydrophilic regimes, ${ }^{[23]}$ opening up the possibility of studying cell attachment or protein adsorption within an extremely large range of wettabilitiy. Figure 5 shows that in the absence of plasma treatment, few cells adhered to the superhydrophobic surfaces (B1) whereas cell attachment is enhanced after $50 \mathrm{~s}$ of Ar-plasma treatment (B2). These results suggest that in this last case the combination of roughness, surface chemistry, and wettability may have a strong influence on cell behavior.

Many biodegradable polymers may crystallize, in which the amount and size of the spherulites may be controlled by adequate thermal histories. PLLA, for example, exhibits quite slow crystallization kinetics, ${ }^{[24]}$ and spherulitic development may be interrupted by quenching below the glass transition temperature, $T_{\mathrm{g}}$. Also, the spherulitic size can be controlled by inducing different nucleation treatments. ${ }^{[25]}$ The control of spherulitic development may be then used to obtain distinct topographies constituted by polygonal elements of different

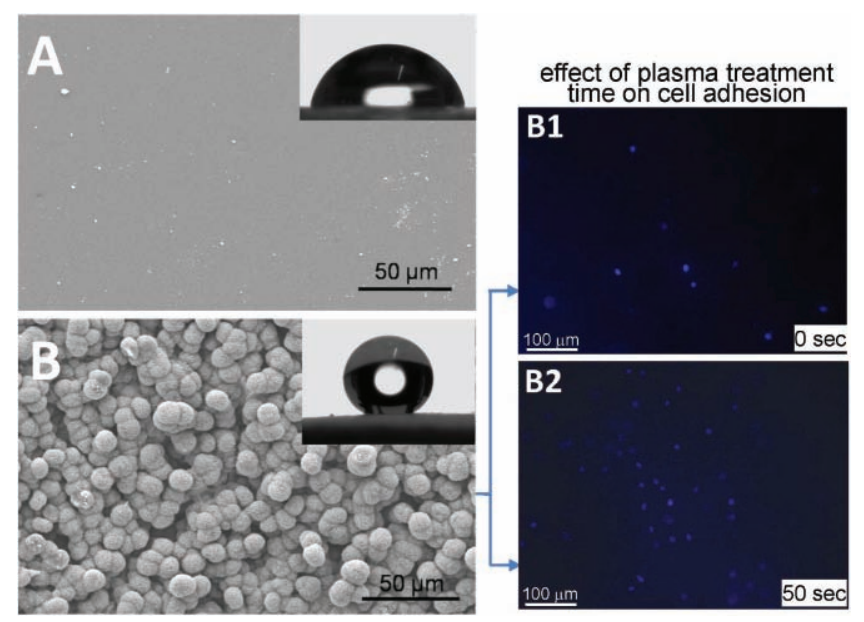

Figure 5. PLLA may be processed into films with surfaces exhibiting smooth (A) and hierarchical rough (B) topographies. Water contact angles (see water droplets profiles in the insets of $A$ and $B$ ) are $71^{\circ}$ and $154^{\circ}$, respectively. Without plasma treatment, the superhydrophobic PLLA surfaces show little ability for cell attachment. B1) Fluorescent microscopy images in which 4,6-diamidino-2-phenylindole (DAPI) was used to stain the nuclei of L929 cells after $24 \mathrm{~h}$ of culture; B2) however, after $50 \mathrm{~s}$ of plasma treatment, the hydrophilicity of the substrate increases and more cells could be observed. Data adapted with permission. ${ }^{[23]}$ sizes. Figure 6A shows the distinct spherulitic textures that were produced in a PLLA flat film upon different treatments. It was found that the adhesion and the cytoskeleton organization of primary human condrocytes were influenced by such different topographies. ${ }^{[26]}$ In particular, it was found that the cells adopted a much more elongated shape when the spherulites were bigger ( $\mathrm{L}$ and $\mathrm{M}$ samples, which also show deeper microgrooves between the spherulites) and a more isotropic organization in the smoother surfaces ( $\mathrm{S}$ and Am; see Figure $6 \mathrm{~B}$ ). Note that such orientation observed in the cells originates from the textured surfaces without any special order, as spherulites are generated randomly throughout the volume of the material, and in the end they are separated from each other by flat front lines. This study suggested that the differences observed could be assigned to the different conformations that proteins adopt upon adsorption to the surfaces showing distinct microtopographies. Such investigations were performed in 2D PLLA films, but we can predict that different topographic features could be generated in the surface of 3D constructs, and that cell behavior could be influenced by them.

When a cell binds to a certain substrate and adhesive linkages are formed, forces are generated by the cytoskeleton to these adhesive bonds, allowing the cell to spread. The magnitude of these forces and the extent of cell spreading are determined by the substrate stiffness, ${ }^{[27]}$ so this parameter can been used to control cell behavior. In fact, some recent works ${ }^{[28]}$ have analyzed the effect and have found that stiffness regulates proliferation and differentiation depending on cell type. For example, myocites differentiate on substrates with intermediate stiffness, but not on substrates with too high or too low stiffness, ${ }^{[28}$ a] and neurons prefer soft substrates. ${ }^{[28 \mathrm{~b}]}$ Wong et al. have prepared acrylamidebased polymeric substrates with stiffness gradients. ${ }^{[29]}$ The simplest methodology involves photopolymerization of the substrate in the presence of a mask with varying opacity. The mask imparts spatial control of light intensity, controlling the degree of crosslinking and the elastic modulus. They found that directional migration of vascular smooth muscle cells can be controlled by tuning the substrate mechanical properties and in this case, the cells migrate preferentially from softer to stiffer regions. ${ }^{[29]}$

A rather simple and effective approach to tailor substrate stiffness is through the layer-by-layer (LbL) technique. ${ }^{[30]}$ An LbL coating can be obtained simply by alternating adsorption of oppositely charged polyelectrolytes. The mechanical properties of the produced coatings can be changed, for example, by a film crosslink. ${ }^{[31]}$ The authors found that long-term proliferation of primary osteoblasts was significantly enhanced in crosslinked, i.e., in more rigid, LbL films constructed using poly(L-lysine) as the polycation and poly(L-glutamic acid), poly(alginic acid), poly(galacturonic acid), or hyaluronan as the polyanions.

The design of materials that combine spatially and temporally controlled stiffness with topographical, chemical, and biomolecular cues could be used in the future to modulate cell behavior. Up to now only a few studies have began to explore this possibility, specifically by proposing the combination of stiffness substrate with surface topography. ${ }^{[32]}$ In 

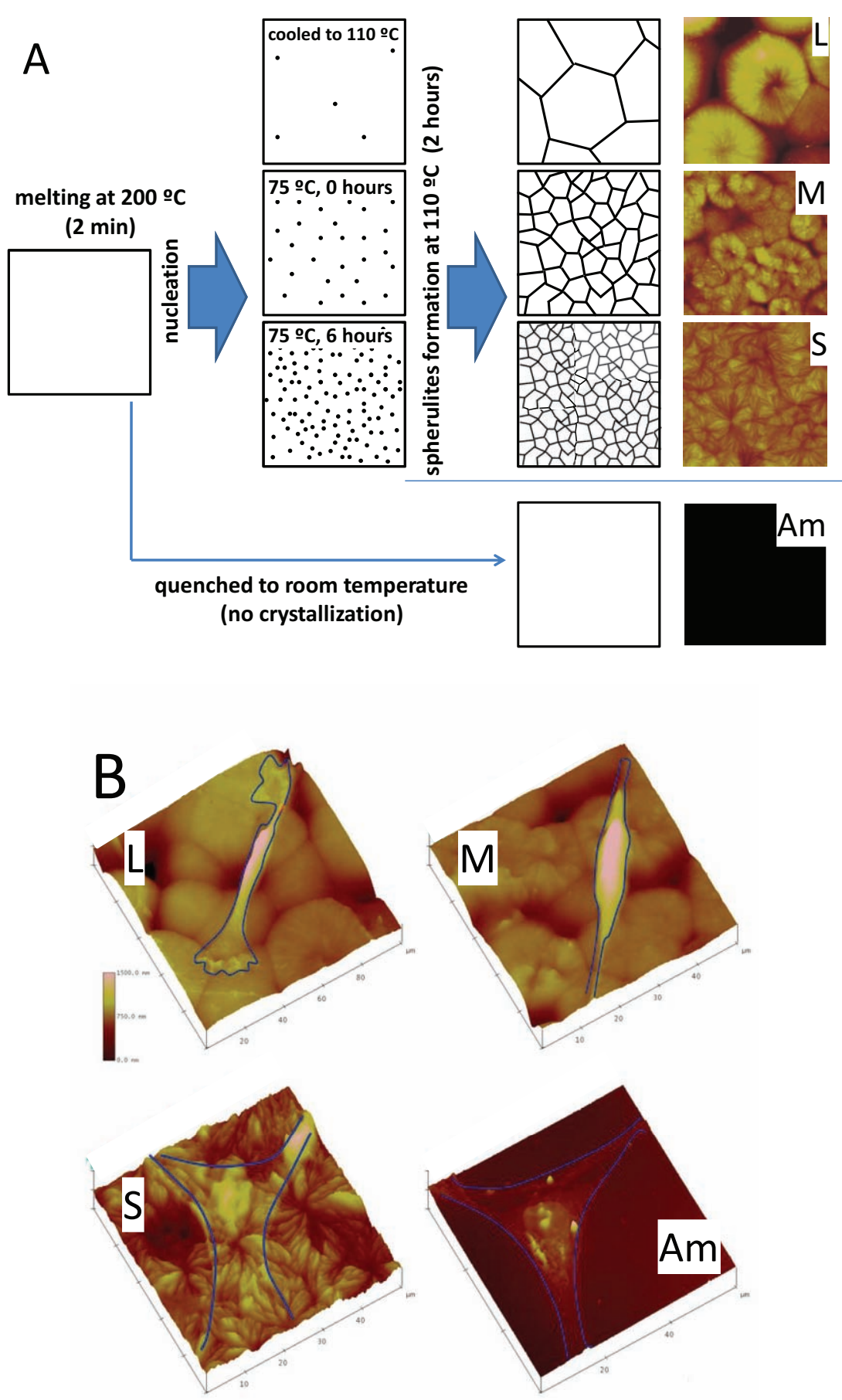

Figure 6. A) Generation of different spherulitic textures on PLLA upon different thermal treatments. The amorphous material (Am) is produced by quenching the melt at room temperature; large spherulites $(\mathrm{L})$ are obtained by directly crystallizing the melt to the crystallization temperature; medium (M) and small (S) spherulites are obtained by a previous nucleation induction by treating the material at $75^{\circ} \mathrm{C}$ for 0 and $6 \mathrm{~h}$, respectively, before the crystallization step. Atomic force microscopy (AFM) images clearly show the different microtopographies obtained. B) Morphology of chondrocytes on the different surfaces as seen by AFM; the lines follow the contour of the cells. Adapted with permission. ${ }^{[26]}$ Copyright 2008, Mary Ann Liebert Inc. Publishers.

particular, Tzvetkova-Chevolleau et al. reported for the first time the synergetic influences of these two effects on both normal and cancer cells. They used polydimethylsiloxane (PDMS) substrates with variable stiffness and patterned with micrometer-scale regions to evaluate the behavior of normal and cancer fibroblastic cells. They found that the dynamics of cell spreading and progressive acquisition of an elongated morphology differ significantly between both types of cells. Normal cells more rapidly reach a polarized shape and keep a larger surface on soft substrates, regardless of the substrate topographies. In contrast, the polarization kinetics and cell surface of cancer cells appeared insensitive to variations in substrate stiffness. However, polarization kinetics of cancer cells was affected by the topography, being faster on the patterned substrates than on an unpatterned environment. The different morphological and dynamical behavior of normal and cancer cells in response to the combined effect of topography and rigidity can lead to significant insights that may suggest strategies for grading the metastatic phenotype of adherent cells. Also, such studies may help the development of a new generation of drugs aiming at inhibiting cancer progression by discriminating cell sensitivity to the ECM topography and rigidity.

\subsection{D Polymer Substrates}

As said before, until now the majority of topography research has been carried out on $2 \mathrm{D}$ surfaces, essentially due to the limitation of the fabrication techniques; this is of course a poor representation of the in vivo environment. However, some examples could be found regarding surface modification in geometrical complex devices. Berry et al. used polymer demixing to prepare nylon tubes with internal nanotopography. ${ }^{[33]}$ The ability to fabricate tubes with nanotopographic features may be useful in many applications such as stents and conduits. These 3D nanotopographic features were found to decrease human osteoprogenitor cell spreading, reduce cytoskeletal organization, and increase endocytotic activity. ${ }^{[33 a]}$ Santos et al. proposed innovative structure bone tissue engineering scaffolds made of a blend of starch and polycaprolactone (PCL), which combines nano- and microfibrous topography. ${ }^{[34]}$ The nanonetwork, fabricated using electrospinning, allowed endothelial cells to span between individual microfibers and influenced cell morphology. Such a structure was found to guide the 3D distribution of endothelial cells being, after implantation, easily available for blood vessel formation. 
Also, this structure does not compromise the structural requirements for bone regeneration. Furthermore, endothelial cells on nano- and microfibers maintained their structural integrity and their intercellular contacts and exhibited a marked angiogenic potential as shown by their ability to form extensive networks of capillarylike structures. The control of cell behavior within a $3 \mathrm{D}$ environment may have a huge potential in future scaffolding design. However, the use of electrospinning to produce nanofibers inside scaffolds may have some limitations if one intends to incorporate them into large porous structures. Other methodologies could be used to produce such nanofeatures, such as self-assembly or the simple freeze-drying of a diluted solution of the polymer previously impregnated into the scaffold. [35]

More techniques are required to produce textures on the surface of 3D structures. An interesting possibility is related to the previously mentioned microtopography based on the formation of spherulites in semicrystalline polymers.

It is unquestionable that the extensive work on the effect of topography on cell behavior improved our comprehension of this issue. It is clear that topography affects cell adhesion, differentiation, proliferation, matrix production, gene expression, cell morphology, and orientation. Topography can provide directional growth for cells and may ultimately create tissue architecture at the cellular and subcellular level in a reproducible manner, so topographical cues could help shorten the tissue formation and reorganization periods. Guidance is also of great importance when we deal with different kinds of cells and when we try to mimic the 3D structure and complexity of the activities in the tissue. The examples given here also point to the fact that the observed effects on cell behavior are extremely dependent not only on the substrate and the features of the micro/nanotexture that is created, but also on the cell type. Consequently, the mechanism governing the varying responses to different surfaces depends on many complex factors; for example, the differences in protein adsorption or in the cytoskeleton arrangement could lead to different responses of distinct cell types when they are put in contact with a given surface topography. As a result, for tissue engineering applications it would be a major breakthrough to discover which substrate topography each cell type preferentially grows on, and to create textured biomaterials in order to selectively propagate a particular cell type and optimize cellular adhesion, proliferation, and other aspects of cell behavior; however, as this section shows, we still have a complex problem without a straightforward solution.

\section{Cell Response to Chemical and Biomolecular Signals}

Upon contact of a biomedical device with a physiological milieu, it is the device's surface that will first come into contact with the surrounding tissues, and therefore it will govern the initial response of the cell/body. However, it is unlikely that cells will make direct contact with the surface of the material. It is well known that proteins from blood or/ and interstitial fluids will cover the material surface almost

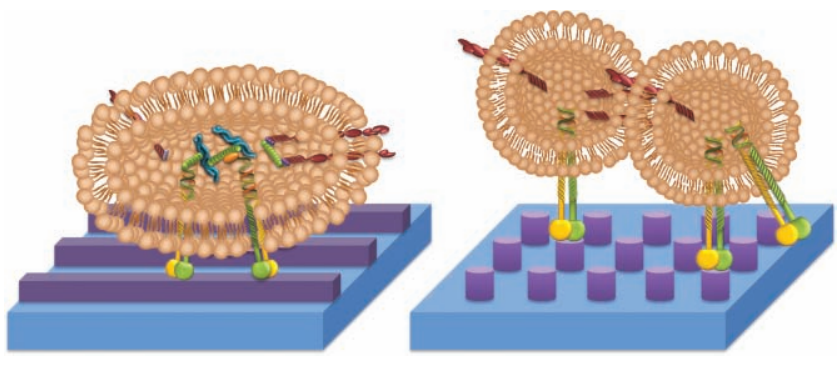

Figure 7. Schematic presentation of patterns which promote (left) or prevent (right) cellular adhesion and spreading.

instantaneously, and it is this proteinaceous layer that will make the surface structure and composition biological. ${ }^{[36]}$ Hence, a way to control the attachment and spreading of cells is by altering the surface chemistry, for example by making patterns that alternatively promote or prevent the adsorption of proteins. ${ }^{[37]}$ The influence of different patterns on bioactive molecules is presented schematically in Figure 7. Cell spreading (left) is observed as a result of integrins clustering and the following formation of focal adhesion and actin stress fibers. In contrast, patterns promoting restricted integrin clustering cause limited cell adhesion and spreading, and eventually cell apoptosis (Figure 7, right).

\subsection{Tailoring Polymer Surfaces to Control Protein Adsorption}

A straightforward approach to engineer patterned surfaces is to first synthesize biologically inert polymer surfaces that significantly reduce or eliminate the nonspecific adsorption of proteins and other biomolecules from biological fluids, and then to pattern domains that are bioactive or stimulate bioactivity. ${ }^{[38,53-60]}$ This approach is particularly useful if multiple proteins are involved in the process. Analysis of a group of mixed self-assembled monolayers (SAMs) presenting different functional groups has suggested that biorepellent functionalities are generally hydrogen bond acceptors, hydrophilic. and overall electrically neutral. ${ }^{[39]}$ In agreement with this finding, the most used polymer to produce nonfouling surfaces or patterns is poly(ethylene glycol) (PEG). Other derivatives of PEG have presented similar behavior. For example, Ho et al. ${ }^{[40]}$ have created protein repealing areas on PLA, PLGA, and chitosan by microcontact printing $(\mu \mathrm{CP})$ of copolymers of oligoethyleneglycol methacrylate and methacrylic acid. They have demonstrated that NIH3T3 fibroblasts remain confined within the patterns on the polymer films for up to 2 weeks and that they align their actin cytoskeleton along the line patterns.

A natural alternative of the repellent PEG surfaces are the lipid bilayers. Peptides and proteins can be embedded and thus provide interesting possibilities for patterning. ${ }^{[38]}$ However, surface-immobilized lipid bilayers suffer one major drawback: they cannot be dried and must therefore always be stored in aqueous solution.

The approach that uses an adhesive background with nonadhesive patterns has been also applied. For example Thisen and co-workers have produced patterns with a resolution 
down to $1 \mu \mathrm{m}$ by laser ablation of poly(ethyleneoxide) grafted onto plasma-polymerized allylamine. ${ }^{[41]}$

\subsection{Patterning Bioactive Elements of the Extracellular Matrix}

Protein adsorption is a rather complex, dynamic process that is difficult to control especially in the physiological environment where many proteins are present and compete with each other. ${ }^{[42]}$ In these conditions, proteins that adsorb more quickly to the surface and are more stable are very often not the best ones for cell survival; therefore, for applications requiring cell adhesion and then proliferation and differentiation, direct patterning of ECM proteins, such as fibronectin, vitronectin, laminin, and collagen, are highly relevant. ${ }^{[43,52-55,58-60]}$ ECM components other than proteins (e.g., glycosaminoglycans) have been also used to create patterned surfaces for different biomedical applications. ${ }^{[44]}$ Laminin was the first micropatterned biomacromolecule. ${ }^{[45]}$ Letourneau and his colleagues have observed ${ }^{[46]}$ that cell adhesiveness of laminin could be inactivated by selective UV irradiation; thus, by simple UV irradiation they created non-adhesive patterns on an adhesive background. In the following years, a variety of techniques were developed ${ }^{[45]}$ to immobilize biomolecules in a site-specific manner onto polymer surfaces with resolutions down to the submicrometer scale. Polymers normally have nonhomogeneous and often dynamic surfaces, restricting the types of successful techniques that can be used to pattern the surfaces; for example, patterning through SAMs, which has been developed for the very organized and homogeneous surfaces of $\mathrm{Au}$ or $\mathrm{Si}$, cannot be applied to polymer substrates. Resist-free lithography is also restricted because of the incompatibility of polymer substrates with organic solvents, which are usually used for photoresist coatings. Techniques ${ }^{[41,47]}$ for applying proteins to polymer surfaces include soft lithography, ${ }^{[6 \mathrm{~b}, 48]}$ complimentary photolithographic techniques, ${ }^{[47]}$ spot arraying, ${ }^{[43,49]}$ direct writing using the tip of an atomic force microscope, ${ }^{[43,50]}$ and colloid arrays. ${ }^{[49,51]}$ Among them, microcontact printing [48c,52-54] from the family of the soft lithography methods is the most used for polymer substrates (Table 1).

Several other factors must also be considered when designing bioactive materials by patterning cell adhesion signals: the presentation of adhesion signals, the average density

Table 1. Some examples of different domains that are bioactive or stimulate bioactivity when patterned polymer substrate. (The data are obtained from 2000-2008 publications).

\begin{tabular}{|c|c|c|c|}
\hline Patterning technique & Substrate & Patterned macromolecule & Application \\
\hline \multirow[t]{10}{*}{ Microcontact printing } & PET & Biotin $(5 \mu \mathrm{m})[48 \mathrm{c}, 52]$ & Printing of bioligands, peptides and proteins \\
\hline & \multirow[t]{2}{*}{ PEG } & Laminin $(15 \mu \mathrm{m})[53]$ & Cell patterning (Rat neonatal cardiomyocytes) \\
\hline & & Biotin derivative $(5 \mu \mathrm{m})[54]$ & Protein microarray \\
\hline & Chitosan & $\begin{array}{l}\text { Oligo(ethylene glycol) methacrylate; } \\
\text { Methacrylic acid }(10 \mu \mathrm{m})[40 \mathrm{~b}]\end{array}$ & $\begin{array}{l}\text { Spatial control and cell organization } \\
\text { (Human microvascular endothelial cells) }\end{array}$ \\
\hline & Poly(HEMA) & Hyaluronic acid $(5 \mu \mathrm{m})[44]$ & $\begin{array}{l}\text { Cell (NIH-3T3 fibrobalsts) and protein } \\
\text { (BSA, FN, IgG) patterns }\end{array}$ \\
\hline & TCPS & Hyaluronic acid $(5 \mu \mathrm{m})[44]$ & $\begin{array}{l}\text { Cell (NIH-3T3 fibrobalsts) and protein } \\
\text { (BSA, FN, IgG) patterns }\end{array}$ \\
\hline & \multirow[t]{2}{*}{ PLGA } & Hyaluronic acid $(5 \mu \mathrm{m})[44]$ & $\begin{array}{l}\text { Cell (NIH-3T3 fibrobalsts) and protein } \\
\text { (BSA, FN, IgG) patterns }\end{array}$ \\
\hline & & $\begin{array}{l}\text { Poly(oligoethyleneglycol methacrylate-co- } \\
\text { methacrylic acid) }(10 \mu \mathrm{m})[40 \mathrm{a}]\end{array}$ & $\begin{array}{l}\text { Spatial organization of cells on tissue } \\
\text { engineering scaffolds (NIH3T3 fibroblasts) }\end{array}$ \\
\hline & Block (PEG-PPG-PEG) & $\mathrm{FN}, \operatorname{lgg}(5 \mu \mathrm{m})[55]$ & $\begin{array}{l}\text { Spatially controlled cell adhesion (Bovine } \\
\text { pulmonary artery endothelial cells) }\end{array}$ \\
\hline & PLA & $\begin{array}{l}\text { Poly(oligoethyleneglycol methacrylate-co- } \\
\text { methacrylic acid) }(10 \mu \mathrm{m}) \text { [40a] }\end{array}$ & $\begin{array}{l}\text { Spatial organization of cells on tissue } \\
\text { engineering scaffolds (NIH3T3 fibroblasts) }\end{array}$ \\
\hline Photochemical patterns & PS & Laminin $(5 \mu \mathrm{m})[37]$ & Cellular arrays (rat Pheochromocytoma cells) \\
\hline \multirow[t]{7}{*}{ Polymer lift-off } & \multirow[t]{2}{*}{ Poly(allylamine) } & Coll I $(1 \mu \mathrm{m})[41]$ & Restricted cell attachment \\
\hline & & FN $(1 \mu \mathrm{m})[41]$ & Restricted cell attachment \\
\hline & \multirow[t]{3}{*}{ TCPS } & PNIPAAm $(30 \times 50 \mu \mathrm{m})[56]$ & Cell arrays (Rat primary hepatocytes) \\
\hline & & Polyacrylamide $\left(20 \mu \mathrm{m}^{2}\right)[57]$ & $\begin{array}{l}\text { Cell-based devices (Bovine carotid artery } \\
\text { endothelial cells) }\end{array}$ \\
\hline & & FN, Gelatin (less than $20 \mu \mathrm{m}$ ) [58] & $\begin{array}{l}\text { Cell patterning (Bovine adrenal capillary } \\
\text { endothelial cells) }\end{array}$ \\
\hline & PET & Tetragylme (down to $25 \mu \mathrm{m}^{2}$ ) [59] & Control of cell shape and size (rat vascular SMC) \\
\hline & Fluorocarbon plasma polymer & Tetragylme (down to $5 \mu \mathrm{m}$ )[60] & Control of cell shape and size (BSA) \\
\hline Colloid arrays & Elastomers & FN $(2 \mu \mathrm{m})[49]$ & Restricted cell attachment (NIH-3T3 fibrobalsts) \\
\hline
\end{tabular}


of the signal, and their spatial distribution. These factors are difficult to control when whole proteins are present on the surfaces. Methods to orient intact proteins and improve function have been developed, and these typically involve an initially immobilized layer that forms complexes with the desired protein that is added afterwards. This task is not easy when working with polymer substrates because of their highly undefined surfaces. Moreover, surfaces of the commonly used biopolymers very often do not have the required functionality for the stable binding of the biological cue, and therefore a loss of activity can occur. For example, simply adsorbed proteins on polymer substrates may be released with time. One approach to overcome this drawback is through chemical immobilization to keep the biological activity of the surface. ${ }^{[61]}$ Chilkoti et al. have developed a new method ${ }^{[48 c, 52]}$ to pattern biological ligands and proteins with micrometer lateral resolution by microstamping a pre-activated polymer surfaces (MAPS). One of the main drawbacks of this method is that upon immobilization of the protein, denaturalization and loss of activity can occur. An alternative approach is the use of shorter peptides instead of intact proteins (Figure 8). Although matrix proteins are large molecules, their major integrin recognition sites are short peptide motifs of only three to six amino acids. Controlling material surface chemistries by mimicking these cell recognition motifs of the same sequence as found in the whole protein may be adequate to invoke a selected cellular response. The best known and most common of these adhesive sequences is arginineglycine-aspartic acid (RGD), firstly discovered ${ }^{[62]}$ in $\mathrm{FN}$, but later identified in other cell-adhesion proteins. Other
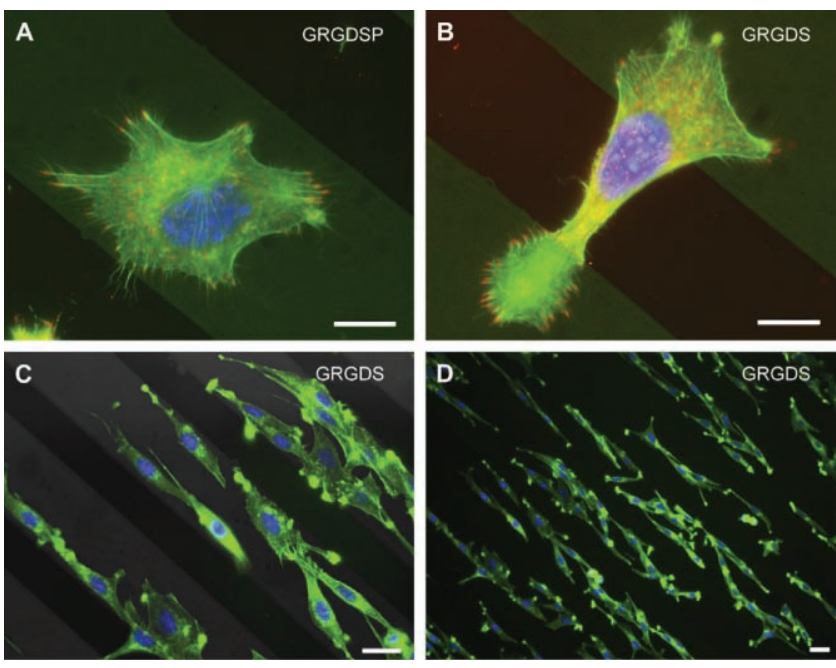

Figure 8. Morphology of cells on structured surfaces. A) Confocal laser microscopy image of fibroblast on Gly-Arg-Gly-Asp-Ser-Pro (GRGDSP)coupled stripe. B) Fluorescence light microscopy image of a fibroblast bridging the Au-ODT stripe and adhering on Gly-Arg-Gly-Asp-Ser (GRGDS)functionalized areas (vinculin staining for focal contacts in red, actin filament labeling with phalloidin in green, staining of nuclei with DAPI in blue). C,D) Cells cultured for 4 (C) and 48 h (D) on GRGDS-functionalized structured surfaces (actin filament labeling with phalloidin-Oregon Green 488, staining of nuclei with DAPI in blue). Scale bars are A,B) $10 \mu \mathrm{m}$ and C,D) $20 \mu \mathrm{m}$. Reprinted from with permission. ${ }^{[66]}$ Copyright 2008, Elsevier. adhesive-recognition peptide sequences such as Tyr-Ile-GlySer-Arg (YIGSR) from laminin B1, ${ }^{[63]}$ Ile-Lys-Val-Ala-Val (IKVAV) in laminin $\mathrm{A}^{[64]}$ or Asp-Gly-Glu-Ala (DGEA) in collagen type ${ }^{[65]}$ have been also used in the design of numerous materials for mediating cell attachment.

The importance of size in chemical patterning must be underlined. While micropatterning targets control single cell behavior (e.g., positioning and growth inside isotropic islands or along anisotropic lines), nanopatterning regulates collective cell behavior (e.g., adhesion, proliferation, gene expression, and differentiation) rather than cell positioning. ${ }^{[67]}$ Why is this different? The fibers of the ECM (10 to $300 \mathrm{~nm}$ in diameter) and their interconnected pores formed in the natural tissues typically have nanoscale dimensions. ${ }^{[68]}$ Cells recognize and adhere to these natural environmental clues via cell adhesion receptors. The size and the spatial organization of these receptors are in the nanoscale. For example, the integrins have a diameter of approximately $10 \mathrm{~nm} .{ }^{[69]}$ Their clustering however is dynamic and the density of the integrin clusters can vary even among the cells adherent on the same surface. ${ }^{[3]}$ Spatz et al. have suggested ${ }^{[70]}$ that the distance between adhesion signals in the range $58-73 \mathrm{~nm}$ is a universal length scale for integrin clustering and activation. This suggests that the design of adhesive surfaces mimicking integrin clustering and the following formation of focal adhesions must be performed in the nanometer regime, ${ }^{[43]}$ more specifically in the range of $5-200 \mathrm{~nm} .{ }^{[70]}$ So far, there is a limited number of methods that allows this high resolution, and this explains why the understanding of focal adhesion and the signalling it evokes has been constricted to the micrometer scale, and in recent years, to submicrometer patches. Keeping in mind the irregular surfaces of polymers, these techniques are even more restricted for polymer surfaces. However, this "disadvantage" of polymer surfaces can be used to design nanostructured surfaces. Properties of the polymer macromolecules, such as their mobility or ability to self-assemble into lamellar, cylindrical, or spherical nanodomains with dimensions from a few nanometers to more than $100 \mathrm{~nm},{ }^{[71]}$ has been already used. For example, Grifith and co-workers ${ }^{[72]}$ have used a very elegant strategy to design comb-shaped copolymers comprising a poly(methyl methacrylate) (PMMA) backbone with short poly(ethylene oxide) PEO side chains (six to nine ethylene oxide units) to present the ligand Gly-Arg-Gly-Asp-Ser-Pro-Lys (GRGDSPK) on the material surface. The hydrophobic PMMA portion establishes a stable surface film in an aqueous environment, whereas the hydrophilic PEO side chains are extended to the water-polymer interface to present adhesion peptides as well as to prevent nonspecific protein adsorption (Figure 9). In such a manner, they have designed different RGD peptide cluster sizes. The overall RGD surface density can be tailored by blending with a polymer without ligand. The authors report that ligand clustering increased cell adhesion strength for a certain ligand density. Additionally, cells reinforced their integrin linkages to withstand stronger detachment force in a manner that depended on ligand clustering.

In a similar approach, Maheshwari et al. ${ }^{[73]}$ functionalized PEG star polymers with an average of 1, 5, and 9 Tyr-GlyArg-Gly-Asp (YGRGD) peptides per star (Figure 10). These 


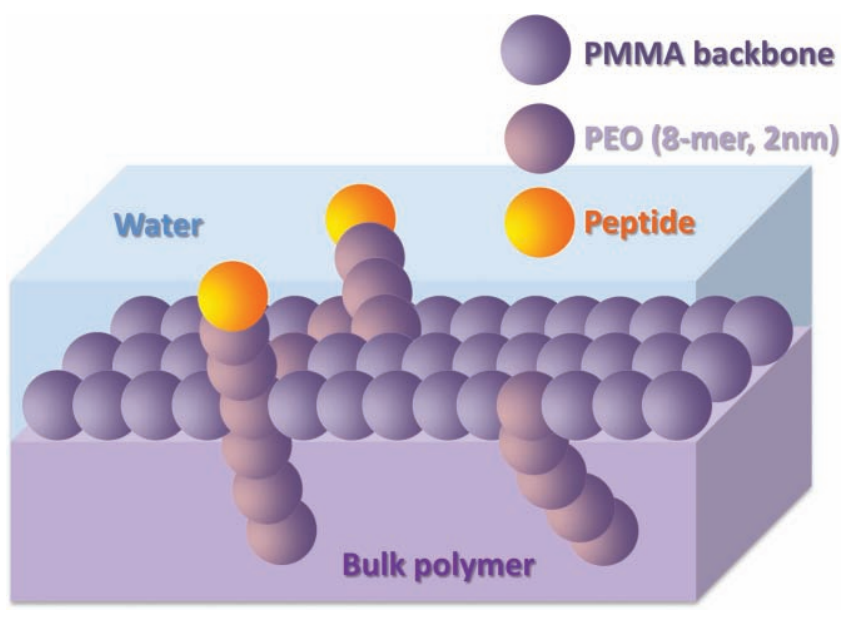

Figure 9. A schematic presentation of peptide-comb structure at the polymer-water interface (based on results in the literature ${ }^{[72]}$ ).

star polymers were mixed with blank stars and immobilized to achieve different overall RGD surface densities. As a result, a significantly higher fraction of fibroblasts showed higher shear stress resistance and exhibited well-formed stress fibers and focal contacts when the ligand was present in a clustered versus a random individual format.

Other techniques for patterning chemical clues at the nanoscale include nanoimprint lithography, ${ }^{[74]}$ dip-pen nanolithography $(\mathrm{DPN}),{ }^{[50]}$ particle lithography, and polymerassisted templating. ${ }^{[3]}$ Recently, an alternative method, which uses a soft elastomeric tip array, rather than tips mounted on individual cantilevers, to deliver inks to a surface in a "direct write" manner was proposed. ${ }^{[75]}$ This method, termed polymer pen lithography, merges the feature-size control of DPN with the large-area capability of contact printing. Moreover, features on the nanometer, micrometer, and macroscopic length scales can be formed with the same tip array.

\section{Smart Textures}

Responsive or smart polymers exhibit sharp and reversible conformational changes with small variations in distinct external signals, such as temperature, $\mathrm{pH}$, ionic strength, or electrical fields. ${ }^{[76]}$ Stimuli-responsive surfaces can be produced by attaching/grafting these kinds of materials onto appropriate substrates. On that basis, smart textures, where

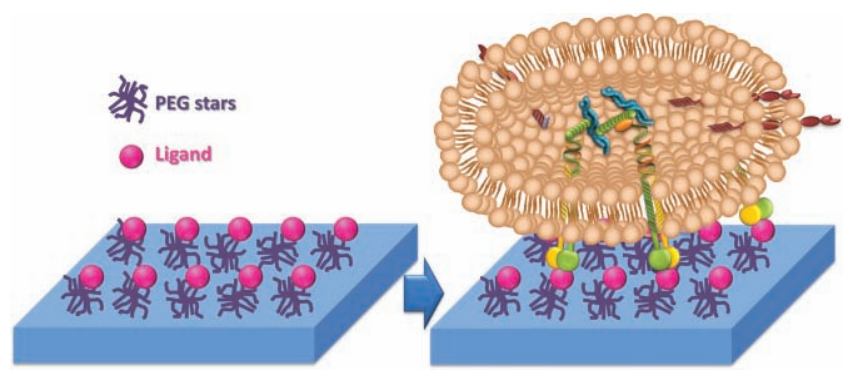

Figure 10. Schematic illustration of star polymers presenting RGD ligands for cell adhesion (based on results in the literature ${ }^{[73]}$ ). the topographical, chemical, or biomolecular cues given to the cells can be controlled and changed by a given stimulus, would be of major relevance. For example, it has been proposed to form smart hydrogels on surfaces in specific patterns that can be used for selective protein adhesion, cell adhesion, and immobilization of drugs or other bioactive agents. ${ }^{[7]}$

The combination of patterning and smart response has been applied to the so-called "cell sheet engineering." Such technology has been proposed to construct ideal transplantable tissues composed exclusively of cells. ${ }^{[78]}$ Initially, Okano and co-workers proposed temperature-responsive cell culture polystyrene substrates prepared by the grafting of thermoresponsive polymers, such as poly ( $N$-isopropylacrylamide) (PNIPAAm), onto these surfaces, which allow the culture of confluent cell monolayers at $37^{\circ} \mathrm{C}$, and their recovery as single cell sheets when the temperature is below the lower critical solubilization temperature (LCST) of PNIPAAm. More recently, they prepared micropatterned thermoresponsive surfaces by photolithographic techniques, ${ }^{[79]}$ in order to establish a construction method for 3D tissues with capillary networks. These surfaces exhibited both PNIPAAm and non-adhesive polyacrylamide (PAAm) domains, and at $37^{\circ} \mathrm{C}$ the endothelial cells selectively adhered to the micropatterned PNIPAAm domains. Stratified tissue equivalents were constructed by layering fibroblast monolayers sheets with micropatterned endothelial cell sheets harvested from the above-mentioned micropatterned surfaces. This resulted in the self-organization of capillary-like networks after a five-day culture period. Another proposed approach was the grafting of PNIPAAm onto substrates that already exhibited micropatterns such as ridges and grooves. ${ }^{[80]}$ They found that most of the seeded endothelial cells were deposited within the grooves immediately after seeding, but they started to move towards the top of the ridges within about $2 \mathrm{~h}$, and finally, selectively adhered to the ridges. On the control substrates, i.e., without PNIPAAm, endothelial cells randomly adhered to both the ridges and grooves of the patterned substrates, suggesting that the presence of a thick layer of PNIPAAm within the grooves plays a significant role in preventing cell adhesion. An interesting feature is that after 2-3 weeks of culture at $37{ }^{\circ} \mathrm{C}$, the endothelial cells show capillary-like tube formation on these thermoresponsive microtextured substrates. Therefore, these distinct approaches to develop thermoresponsive patterns are very promising for providing more insights into cell-cell communications and angiogenesis in reconstructed, 3D environments, as well for the fabrication of tissues with complex, multicellular architecture.

Also, with the aim of fabricating complicated 3D tissues, novel micropatterned dual thermoresponsive surfaces that enable the culture and recovery of patterned heterotopic cell sheets were proposed.[81] Two types of thermoresponsive polymers exhibiting different LCSTs, PNIPAAm, and $n$-butylmethacrylate (BMA)-co-grafted PNIPAAm, were micropatterned using electron beam polymerization. The hydrophilic/hydrophobic changes exhibited by these surfaces as a function of temperature allowed the selective adhesion and growth of rat primary hepatocytes and bovine carotid endothelial cells. At $27{ }^{\circ} \mathrm{C}$, the hepatocytes only adhered to the hydrophobic poly(NIPAAm-co-BMA). When the 
temperature increased to $37{ }^{\circ} \mathrm{C}$, the sequential seeding of endothelial cells allowed exclusive adhesion to the hydrophobized PNIPAAm regions, resulting in patterned co-cultures. The co-cultured and patterned cell sheets could be recovered when the temperature is low enough to allow the hydration of both polymer-grafted domains (in this case at $20^{\circ} \mathrm{C}$ ). These cell sheets can be combined with other co-culture cell sheets, and ultimately, could provide a new technology to regenerate complex organs such as liver and kidneys.

Although the methods employed by Okano and co-workers to obtain patterned cell sheets, provided sufficient reproducibility and resolution, they were more timeconsuming or complex than desired. In order to overcome these features, they recently used microcontact printing to produce fibronectin micropatterns directly onto commercially available thermoresponsive PNIPAAm culture dishes. ${ }^{[2]}$ Patterns with different sizes and shapes in the ranges of 20-500 $\mu \mathrm{m}$ were successfully fabricated with a cheaper and more straightforward methodology. Primary rat hepatocytes seeded on these patterned surfaces, in a serum-free medium, attached only to the fibronectin domains. ${ }^{[82 \mathrm{~b}]}$ Endothelial cells were then seeded on the dishes, and it was observed that they attach onto the intervals between the hepatocytes; that is, a micropatterned co-culture of hepatocytes and endothelial cells was successfully achieved. ${ }^{[82 b]}$ Moreover, all the cells were harvested as a single micropatterned cell sheet and transferred onto new dishes. Okano et al. already showed that it is possible to obtain cell sheet constructs with five layers, where the viability of the transferred cells and the adequate organization of the functional cell-cell junctions were demonstrated. ${ }^{[79]}$ As a result, this new approach could be undoubtedly very promising to fabricate thick cell sheet constructs with the complex tissue-like microstructure.

The proper function of many tissues depends critically on the structural organization of the cells and ECM. Okano et al. showed that micropatterned, thermoresponsive polystyrene substrates can also be used to generate cell sheets with defined ECM/cell organization. ${ }^{[83]}$ The patterns consisted of parallel grooves $5 \mu \mathrm{m}$ in depth, $50 \mu \mathrm{m}$ wide, and spaced $50 \mu \mathrm{m}$ apart. Vascular smooth muscle cells cultured on these substrates produced sheets consisting of cells that exhibited strong alignment in the direction of the grooves. The authors found that there is an optimum range of PNIPAAm graft density $(45-50 \%)$ that has to be used in order to obtain these cell sheets. The sheets could be easily transferred from patterned to nonpatterned substrates without the loss of tissue organization. Although this work was introduced within the framework of developing a tissue engineered vascular graft there are many tissue engineering (TE) applications where this approach could be potentially applicable. For instance, as the cardiac wall comprises multiple layers of highly aligned cardiac muscle, such sheets could be used in cardiac TE for infarct repair. Skeletal muscle engineering would also benefit from such an aligned construct. Parallel groove patterns are suitable for blood vessel and muscle applications, but of course, other distinct and more complex patterns could be used, depending on the application.

Aligned cell sheets were also developed by Dang and Leong. ${ }^{[84]}$ In this work, aligned nanofibers composed of thermoresponsive hydroxybutyl chitosan were electrospun to create a scaffold for the production of this type of cell sheets. The median fiber diameter was $436 \mathrm{~nm}$, and their alignment created repetitively spaced nanometer-scale features at the scaffold surface. Human mesenchymal stem cells (hMSC) cultured on these surfaces presented alignment and elongation in both the cell body and nucleus. Besides these morphological changes, topographical features induced the expression of genes indicative of myogenic induction of hMSC cultured in proliferative, nondifferentiating medium. The thermoresponsive character of the polymer used allowed its dissolution from the cell/scaffold construct without disruption of the cytoskeletal structure and cellcell interactions. Bioactive components, such as natural matrix components and growth factors, could be incorporated into the fibers during fabrication in order to obtain a surface with biochemical cues, which could enhance cellular function. This strategy could create, after dissolution of the scaffold, a cell sheet tailored with the desired levels of cell maturation and tissue response to the given biochemical and topographical cues. We believe that the introduction of topographical cues, alone or combined with chemical and biomolecular signals, in order to create aligned cell sheets may have a tremendous impact in engineering tissue constructs in the future.

Smart textured surfaces can also be used to control and trigger the occurrence of biomineralization in biodegradable substrates. ${ }^{[85]}$ In this case, temperature was used as the external stimulus. The principle was based on the change of the conformational features of PNIPAAm chains across the LCST, synthesized over a bioactive composite substrate by using plasma activation. By patterning the modification of the surface, it was possible ${ }^{[85]}$ to combine temperature and spatial control of biomimetic apatite formation. This was achieved by just exposing some regions of the substrate surface to the plasma treatment, allowing the insertion of PNIPAAm in specifically desired areas. It was shown ${ }^{[86]}$ that apatite-coated surfaces enable the attachment, growth, and expression of osteogenic genes in osteoblastlike cells. Thus, apatite-patterned surfaces, such as the ones developed in the above-mentioned work, could be used in fundamental studies on differentiation, adhesion, proliferation, and cellcell signaling of bone-related cells. These surfaces could also be used in fundamental co-culture studies involving bone cells and other kind of cells such as endothelial cells, which could be useful in bone tissue engineering applications. Of course, the selective activation of the surface could be performed using other techniques (e.g., photolithography).

Other thermoresponsive polymers may be used instead of PNIPAAm. For example, smart thin coatings using a recombinant elastinlike polymer (ELP) containing RGD sequences were fabricated through simple deposition of the ELP dissolved in aqueous-based solutions onto chitosan membranes. ${ }^{[87]}$ It was shown that the conformational changes suffered by the ELP at its inverse temperature transition modified the topography at the nanoscale and the wettability of the polymeric substrate, which could be potentially used to control cell adhesion and protein adsorption. 


\section{Future Trends}

Distinct methods and strategies to tailor polymeric substrates with topographical, chemical, and biomolecular signals have been discussed in this review. From the extensive work developed by many researchers, it is evident that the majority of the studies have been performed on 2D surfaces, mainly due to the limitations of fabrication techniques. Additional and continuing advances in micro- and nanofabrication, as well as in other technologies, are under development. It is expected that by applying these technologies, it would be possible to translate the advanced $2 \mathrm{D}$ models into $3 \mathrm{D}$ structures that could more efficiently mimic the in vivo environment. Important outcomes are also expected from the fast developing area of smart surfaces responsive to different stimuli. These kinds of surfaces will be of great importance as they will help us understand cell behavior in a dynamic environment, similar to the in vivo environment. Finally, a major challenge will be to integrate the distinct signals, i.e., topographical, chemical, and biomolecular, in order to obtain highly defined surfaces that will allow precise mimicking of the timing and metabolic course of naturally occurring processes involved in cell survival and development.

\section{Acknowledgements}

The research leading to these results has received partial funding from the European Union Seventh Framework Programme (FP7/2007-2013) under grant agreement no. NMP4SL-2009-229292 and by the FCT projects PTDC/FIS/68517/2006, PTDC/QUI/69263/2006, PTDC/FIS/68209/2006, and PTDC/ QUI/68804/2006.

[1] E. Drexler, Engines of creation: The coming era of nanotechnology, Anchor Books Edition, New York 1986.

[2] a) P. Girard, E. Cavalcanti-Adam, R. Kemkemer, J. Spatz, Soft Matter 2007, 3, 307-326; b) C. A. Parent, P. N. Devreotes, Science 1999, 284, 765-770.

[3] J. P. Spatz, B. Geiger, Method. Cell. Biol. 2007, 83, 89-111.

[4] H. G. Craighead, C. D. James, A. M. P. Turner, Curr. Opin. Solid St. Mater. 2001, 5, 177-184.

[5] a) M. J. Dalby, M. O. Riehle, H. Johnstone, S. Affrossman, A. S. G. Curtis, Biomaterials 2002, 23, 2945-2954; b) M. J. Dalby, S. Childs, M. O. Riehle, H. J. H. Johnstone, S. Affrossman, A. S. G. Curtis, Biomaterials 2003, 24, 927-935; c) S. Jungbauer, R. Kemkemer, H. Gruler, D. Kaufmann, J. P. Spatz, ChemPhysChem 2004, 5, 85-92.

[6] a) K. R. Milner, C. A. Siedlecki, J. Biomed. Mater. Res. A 2007, 82A, 80-91; b) C. D. W. Wilkinson, M. Riehle, M. Wood, J. Gallagher, A. S. G. Curtis, Mater. Sci. Eng C 2002, 19, 263-269.

[7] S. Ber, G. T. Kose, V. Hasirci, Biomaterials 2005, 26, 1977-1986.

[8] W. A. Loesberg, J. te Riet, F. C. M. J. M. van Delft, P. Schon, C. G. Figdor, S. Speller, J. J. W. A. van Loon, X. F. Walboomers, J. A. Jansen, Biomaterials 2007, 28, 3944-3951.

[9] Y. Q. Wan, Y. Wang, Z. M. Liu, X. Qu, B. X. Han, J. Z. Bei, S. G. Wang, Biomaterials 2005, 26, 4453-4459.

[10] C. C. Berry, G. Campbell, A. Spadiccino, M. Robertson, A. S. G. Curtis, Biomaterials 2004, 25, 5781-5788.
[11] A. M. P. Turner, N. Dowell, S. W. P. Turner, L. Kam, M. Isaacson, J. N. Turner, H. G. Craighead, W. Shain, J. Biomed. Mater. Res. 2000, 51, 430-441.

[12] I. Y. Tsai, A. J. Crosby, T. P. Russell, Method Cell Biol. 2007, 83, 67-87.

[13] a) M. J. Dalby, D. Giannaras, M. O. Riehle, N. Gadegaard, S. Affrossman, A. S. G. Curtis, Biomaterials 2004, 25, 77-83; b) J. Y. Lim, A. D. Dreiss, Z. Y. Zhou, J. C. Hansen, C. A. Siedlecki, R. W. Hengstebeck, J. Cheng, N. Winograd, H. J. Donahue, Biomaterials 2007, 28, 1787-1797; c) J. Y. Lim, J. C. Hansen, C. A. Siedlecki, R. W. Hengstebeck, J. Cheng, N. Winograd, H. J. Donahue, Biomacromolecules 2005, 6, 3319-3327.

[14] a) J. P. Spatz, P. Eibeck, S. Mossmer, M. Moller, E. Y. Kramarenko, P. G. Khalatur, I. I. Potemkin, A. R. Khokhlov, R. G. Winkler, P. Reineker, Macromolecules 2000, 33, 150-157; b) H. L. Khor, Y. Kuan, H. Kukula, K. Tamada, W. Knoll, M. Moeller, D. W. Hutmacher, Biomacromolecules 2007, 8, 1530-1540.

[15] M. T. Eliason, E. O. Sunden, A. H. Cannon, S. Graham, A. J. Garcia, W. P. King, J. Biomed. Mater. Res. A 2008, 86A, 996-1001.

[16] Z. W. Ma, M. Kotaki, R. Inai, S. Ramakrishna, Tissue Eng. 2005, 11, 101-109.

[17] a) S. P. Zhong, W. E. Teo, X. Zhu, R. W. Beuerman, S. Ramakrishna, L. Y. L. Yung, J. Biomed. Mater. Res. A 2006, 79A, 456-463; b) S. Y. Chew, R. Mi, A. Hoke, K. W. Leong, Biomaterials 2008, 29, 653-661.

[18] C. Y. Xu, F. Yang, S. Wang, S. Ramakrishna, J. Biomed. Mater. Res. A 2004, 71A, 154-161.

[19] G. R. Owen, J. Jackson, B. Chehroudi, H. Burt, D. M. Brunette, Biomaterials 2005, 26, 7447-7456.

[20] a)Y. Arima, H. Iwata, Biomaterials 2007, 28, 3074-3082; b) D. S. W. Benoit, M. P. Schwartz, A. R. Durney, K. S. Anseth, Nat. Mater. 2008, 7, 816-823; c) J. Y. Lim, M. C. Shaughnessy, Z. Y. Zhou, H. Noh, E. A. Vogler, H. J. Donahue, Biomaterials 2008, 29, 1776-1784.

[21] J. L. E. Ivirico, M. Salmeron-Sanchez, J. L. G. Ribelles, M. M. Pradas, J. M. Soria, M. E. Gomes, R. L. Reis, J. F. Mano, J. Biomed. Mater. Res. B 2009, 91B, 277-286.

[22] N. M. Alves, J. Shi, E. Oramas, J. L. Santos, H. Tomas, J. F. Mano, J. Biomed. Mater. Res. A 2009, 91A, 480-488.

[23] W. L. Song, D. D. Veiga, C. A. Custodio, J. F. Mano, Adv.Mater. 2009, 21, 1830.

[24] a) Y. Wang, J. L. G. Ribelles, M. S. Sanchez, J. F. Mano, Macromolecules 2005, 38, 4712-4718; b) M. S. Sanchez, J. L. G. Ribelles, F. H. Sanchez, J. F. Mano, Thermochimica Acta 2005, 430, 201-210.

[25] F. H. Sanchez, J. M. Mateo, F. J. R. Colomer, M. S. Sanchez, J. L. G. Ribelles, J. F. Mano, Biomacromolecules 2005, 6, 3283-3290.

[26] E. C. Martinez, J. C. R. Hernandez, M. Machado, J. F. Mano, J. L. G. Ribelles, M. M. Pradas, M. S. Sanchez, Tissue Eng. A 2008, 14, 1751-1762.

[27] T. Yeung, P. C. Georges, L. A. Flanagan, B. Marg, M. Ortiz, M. Funaki, N. Zahir, W. Y. Ming, V. Weaver, P. A. Janmey, Cell Motility and the Cytoskeleton 2005, 60, 24-34.

[28] a) A. J. Engler, M. A. Griffin, S. Sen, C. G. Bonnetnann, H. L. Sweeney, D. E. Discher, J. Cell Biol. 2004, 166, 877-887; b) A. P. Balgude, X. Yu, A. Szymanski, R. V. Bellamkonda, Biomaterials 2001, 22, 1077-1084.

[29] J. Y. Wong, A. Velasco, P. Rajagopalan, Q. Pham, Langmuir 2003, 19, 1908-1913.

[30] C. Picart, Curr. Med. Chem. 2008, 15, 685-697.

[31] a) C. P. Vazquez, T. Boudou, V. Dulong, C. Nicolas, C. Picart, K. Glinel, Langmuir 2009, 25, 3556-3563; b) C. Picart, R. Elkaim, L. Richert, T. Audoin, Y. Arntz, M. D. Cardoso, P. Schaaf, J. C. Voegel, B. Frisch, Adv. Funct. Mater. 2005, 15, 83-94.

[32] a) E. J. Semler, C. S. Ranucci, P. V. Moghe, Adv. Biochem. Eng. Biotech. 2006, 102, 1-46; b) T. Tzvetkova-Chevolleau, A. Stephanou, 
D. Fuard, J. Ohayon, P. Schiavone, P. Tracqui, Biomaterials 2008 , 29, 1541-1551.

[33] a) C. C. Berry, M. J. Dalby, R. O. C. Oreffo, D. McCloy, S. Affrosman, J. Biomed. Mater. Res. A 2006, 79A, 431-439; b) C. C. Berry, M. J. Dalby, D. McCloy, S. Affrossman, Biomaterials 2005, 26, 4985-4992.

[34] M. I. Santos, K. Tuzlakoglu, S. Fuchs, M. E. Gomes, K. Peters, R. E. Unger, E. Piskin, R. L. Reis, C. J. Kirkpatrick, Biomaterials 2008, 29, 4306-4313.

[35] M. Prabaharan, M. A. Rodriguez-Perez, J. A. de Saja, J. F. Mano, J. Biomed. Mater. Res. B 2007, 81B, 427-434.

[36] a) C. J. Wilson, R. E. Clegg, D. I. Leavesley, M. J. Pearcy, Tissue Eng. 2005, 11, 1-18; b) D. L. Elbert, J. A. Hubbell, Annu. Rev. Mater. Sci. 1996, 26, 365-394.

[37] A. Welle, S. Horn, J. Schimmelpfeng, D. Kalka, J. Neurosci. Meth. 2005, 142, 243-250.

[38] D. Falconnet, G. Csucs, H. M. Grandin, M. Textor, Biomaterials 2006, 27, 3044-3063.

[39] a) E. Ostuni, R. G. Chapman, R. E. Holmlin, S. Takayama, G. M. Whitesides, Langmuir 2001, 17, 5605-5620; b) E. Ostuni, R. G. Chapman, N. M. Liang, G. Meluleni, G. Pier, D. E. Ingber, G. M. Whitesides, Langmuir 2001, 17, 6336-6343; c) E. Ostuni, B. A. Grzybowski, M. Mrksich, C. S. Roberts, G. M. Whitesides, Langmuir 2003, 19, 1861-1872.

[40] a) C. C. Lin, C. C. Co, C. C. Ho, Biomaterials 2005, 26, 3655-3662; b) G. Kumar, Y. C. Wang, C. Co, C. C. Ho, Langmuir 2003, 19, 10550-10556.

[41] H. Thissen, J. P. Hayes, P. Kingshott, G. Johnson, E. C. Harvey, H. J. Griesser, Smart Mater. Struct. 2002, 11, 792-799.

[42] M. Mrksich, G. M. Whitesides, Annu. Rev. Biophys. Biomol. Struct. $1996,25,55-78$

[43] K. L. Christman, V. D. Enriquez-Rios, H. D. Maynard, Soft Matter 2006, 2, 928-939.

[44] K. Y. Suh, A. Khademhosseini, J. M. Yang, G. Eng, R. Langer, Adv. Mater. 2004, 16, 584-588.

[45] A. Folch, M. Toner, Annu. Rev. Biomed. Eng. 2000, 2, 227-256.

[46] a) J. A. Hammarback, J. B. Mccarthy, S. L. Palm, L. T. Furcht, P. C. Letourneau, Developmental Biology 1988, 126, 29-39; b) J. A. Hammarback, S. L. Palm, L. T. Furcht, P. C. Letourneau, J. Neurosci. Res. 1985, 13, 213-220.

47] A. S. Blawas, W. M. Reichert, Biomaterials 1998, 19, 595-609.

[48] a) A. J. Torres, M. Wu, D. Holowka, B. Baird, Annu. Rev. Biophys. 2008, 37, 265-288; b) Y. Xia, G. M. Whitesides, Annu. Rev. Mater. Sci. 1998, 28, 153-184; c) Z. P. Yang, A. Chilkoti, Adv. Mater. $2000,12,413$.

[49] N. J. Gleason, C. J. Nodes, E. M. Higham, N. Guckert, I. A. Aksay, J. E. Schwarzbauer, J. D. Carbeck, Langmuir 2003, 19, 513-518.

[50] R. D. Piner, J. Zhu, F. Xu, S. H. Hong, C. A. Mirkin, Science 1999, 283, 661-663.

[51] M. Textor, R. Michel, J. Voros, J. A. Hubbell, J. Lussi, US 2005/0014151 A1, 2005.

[52] J. Hyun, Y. J. Zhu, A. Liebmann-Vinson, T. P. Beebe, A. Chilkoti, Langmuir 2001, 17, 6358-6367.

[53] Y. V. Pan, T. C. McDevitt, T. K. Kim, D. Leach-Scampavia, P. S. Stayton, D. D. Denton, B. D. Ratner, Plasmas Polym. 2002, 7, 171-183.

[54] J. Groll, W. Haubensak, T. Ameringer, M. Moeller, Langmuir 2005 , 21, 3076-3083.

[55] J. L. Tan, W. Liu, C. M. Nelson, S. Raghavan, C. S. Chen, Tissue Eng. 2004, 10, 865-872.

[56] M. Yamato, C. Konno, S. Koike, Y. Isoi, T. Shimizu, A. Kikuchi, K. Makino, T. Okano, J. Biomed. Mater. Res. 2003, 67A, 1065-1071.

[57] S. Iwanaga, Y. Akiyama, A. Kikuchi, M. Yamato, K. Sakai, T. Okano, Biomaterials 2005, 26, 5395-5404.

[58] E. Ostuni, R. Kane, C. S. Chen, D. E. Ingber, G. M. Whitesides, Langmuir 2000, 16, 7811-7819.

[59] A. Goessl, D. F. Bowen-Pope, A. S. Hoffman, J. Biomed. Mater. Res. 2001, 57, 15-24.
[60] a) A. Goessl, M. D. Garrison, J. B. Lhoest, A. S. Hoffman, J. Biomat. Sci. Polymer Ed. 2001, 12, 721-738; b) A. Goessl, S. L. Golledge, A. S. Hoffman, J. Biomat. Sci. Polymer Ed. 2001, 12, 739-753.

[61] C. A. Custodio, C. M. Alves, R. L. Reis, J. F. Mano, J. Tissue Eng. Reg. Med. 2010, in press.

[62] M. D. Pierschbacher, E. Ruoslahti, Nature 1984, 309, 30-33.

[63] J. Graf, R. C. Ogle, F. A. Robey, M. Sasaki, G. R. Martin, Y. Yamada, H. K. Kleinman, Biochemistry 1987, 26, 6896-6900.

[64] K. Tashiro, G. C. Sephel, B. Weeks, M. Sasaki, G. R. Martin, H. K. Kleinman, Y. Yamada, J. Biol. Chem. 1989, 264, 16174-16182.

[65] W. D. Staatz, K. F. Fokg, M. M. Zutter, S. P. Adams, B. A. Rodriguez, S. A. Santoro, J. Biol. Chem. 1991, 266, 7363-7367.

[66] S. Kalinina, H. Gliemann, M. Lopez-Garcia, A. Petershans, J. Auernheimer, T. Schimmel, M. Bruns, A. Schambony, H. Kessler, D. Wedlich, Biomaterials 2008, 29, 3004-3013.

[67] J. Y. Lim, H. J. Donahue, Tissue Eng. 2007, 13, 1879-1891.

[68] M. M. Stevens, J. H. George, Science 2005, 310, 1135-1138.

[69] M. A. Arnaout, B. Mahalingam, J.-P. Xiong, Annu. Rev. Cell Dev. Biol. 2005, 21, 381-410.

[70] M. Arnold, E. A. Cavalcanti-Adam, R. Glass, J. Blummel, W. Eck, M. Kantlehner, H. Kessler, J. P. Spatz, ChemPhysChem 2004, 5, 383-388.

[71] a) Y. Zhang, S. Raoux, D. Krebs, L. E. Krupp, T. Topuria, M. A. Caldwell, D. J. Milliron, A. Kellock, P. M. Rice, J. L. Jordan-Sweet, H. S. P. Wong, J. Appl. Phys. 2008, 104, 074312; b) N. Kumar, J. I. Hahm, Langmuir 2005, 21, 6652-6655.

[72] L. Y. Koo, D. J. Irvine, A. M. Mayes, D. A. Lauffenburger, L. G. Griffith, J. Cell Sci. 2002, 115, 1423-1433.

[73] G. Maheshwari, G. Brown, D. A. Lauffenburger, A. Wells, L. G. Griffith, J. Cell Sci. 2000, 113, 1677-1686.

[74] S. Y. Chou, P. R. Krauss, P. J. Renstrom, Science 1996, 272, 85-87.

[75] F. W. Huo, Z. J. Zheng, G. F. Zheng, L. R. Giam, H. Zhang, C. A. Mirkin, Science 2008, 321, 1658-1660.

[76] a) E. S. Gil, S. A. Hudson, Prog. Polym. Sci. 2004, 29, 1173-1222; b) J. F. Mano, Adv. Eng. Mater. 2008, 10, 515-527.

[77] Y. Nakayama, M. Takatsuka, T. Matsuda, Langmuir 1999, 15, 1667-1672.

[78] a) N. Matsuda, T. Shimizu, M. Yamato, T. Okano, Adv. Mater. 2007, 19, 3089-3099; b) R. M. P. Da Silva, J. F. Mano, R. L. Reis, Trends Biotech. 2007, 25, 577-583.

[79] Y. Tsuda, T. Shimizu, M. Yarnato, A. Kikuchi, T. Sasagawa, S. Sekiya, J. Kobayashi, G. Chen, T. Okano, Biomaterials 2007, 28, 4939-4946.

[80] Y. Tsuda, M. Yamato, A. Kikuchi, M. Watanabe, G. P. Chen, Y. Takahashi, T. Okano, Adv. Mater. 2007, 19, 3633.

[81] a) Y. Tsuda, A. Kikuchi, M. Yamato, A. Nakao, Y. Sakurai, M. Umezu, T. Okano, Biomaterials 2005, 26, 1885-1893; b) Y. Tsuda, A. Kikuchi, M. Yamato, G. P. Chen, T. Okano, Biochem. Bioph. Res. Co 2006, 348, 937-944.

[82] a) C. Williams, Y. Tsuda, B. C. Isenberg, M. Yamato, T. Shimizu, T. Okano, J. Y. Wong, Adv. Mater. 2009, 21, 2161; b) I. E. Hannachi, K. Itoga, Y. Kumashiro, J. Kobayashi, M. Yamato, T. Okano, Biomaterials 2009, 30, 5427-5432.

[83] B. C. Isenberg, Y. Tsuda, C. Williams, T. Shimizu, M. Yamato, T. Okano, J. Y. Wong, Biomaterials 2008, 29, 2565-2572.

[84] J. M. Dang, K. W. Leong, Adv. Mater. 2007, 19, 2775.

[85] J. Shi, N. M. Alves, J. F. Mano, Adv. Funct. Mater. 2007, 17, 3312-3318.

[86] a) Y. F. Chou, W. B. Huang, J. C. Y. Dunn, T. A. Miller, B. M. Wu, Biomaterials 2005, 26, 285-295; b) D. Richard, N. Dumelie, H. Benhayoune, S. Bouthors, C. Guillaume, N. Lalun, G. Balossier, D. Laurent-Maquin, J. Biomed. Mater. Res. B 2006, 79B, 108-115.

[87] R. R. Costa, C. A. Custodio, A. M. Testero, F. J. Arias, J. C. Rodriguez-Cabello, N. M. Alves, J. F. Mano, Adv. Funct. Mater. 2009, 19, 3210-3218.

Received: February 12, 2010 Published online:

www.small-journal.com 